\title{
ESTUDO DESCRITIVO DO SUICíDIO NO MUNICÍPIO DE SÃO PAULO (BRASIL) - 1959 A 1968
}

Victório BARBOSA *

\begin{abstract}
Barbosa, V. - Estudo descritivo do suicídio no municipio de São Paulo (Brasil)
\end{abstract} - 1959 a 1968. Rev. Saúde públ., S. Panlo, 8:1-1\%. 19\%4.

Resumo: Foi feito estudo epidemiológico retrosyectivo descritivo de mortalidade por suicidio no município de São Paulo, Brasil, baseado nos dados oficiais. Foram estudadas as tendencias de alguns caracteres epidemiológicos dessa causa de morte nos anos de 1959 a 1968: causas exógena, distribuição cronológica, distribuição causal e distribuiçáo por sexo e idade.

Unitermos: Suicidio*: Mortalidade* Epidemologia*.

Este trabalho consiste de um estudo epidemiológico retrospectivo descritivo da causa de morte por suicídio, no período de 1959 a 1968, essencialmente baseado nos dados oficiais.

Os motivos que nos levaram a apresentá-lo foram, em resumo. os seguintes: (1) continuar a série de estudos que nos propusemos fazer a respeito. iniciada em 1965 com o trabalho de Rarros \& Barbosi $(1965)^{2}$; (2) divulgar dados de mortalidade sobre o suicídio em nosso município, atualizados. até o ano mais próximo possivel, de acordo com a disponibilidade dos dados oficiais na prática. Esta divulgação tem. por sua vez, um duplo propósito: (a) apontar a presença de aspectos epidemiológicos importantes do comportamento da mortalidade por suicídio entre nós. no que tange à sua erolução temporal e no que diz respeito à distribuição dessa causa de morte em relação ao sexo, idade. causas exógenas e rariação estacional, no período considerado; (b) fornecer dados que servirão de pontos de referência, para efeito de comparação, com dados de estudo sobre o suicídio que pretendemos iniciar no futuro, partindo das informações anotadas em questionário específico. colhidas - por entrevistas - dos familiares dos casos recentes de suicídio ocorridos no município de São Paulo.

\section{MATERIAL E METODOS}

Adotaremos a $7 .^{\text {a }}$ Revisão da Classificação Estatística Internacional de Doenças. Lesões e Causas de óbito $(1964)^{1}$, a qual classifica o suicipio e a tentativa de

\footnotetext{
* Do Departamento de Epidemiologia da Faculdade de Saúde Pública da USP - Av. Dr. Arnaldo, 715 - São Paulo, SP - Brasil.
} 
BARbosa, V. - Estudo descritivo do suicídio no municiplo de São Paulo (Brasil) - 1959 a 1968. Rev. Saúde públ., S. Paulo, 8: 1-14, 1974.

suicídio em 10 grupos de causas exógenas, a saber:

E-970 - suicídio e envenenamento autoinflingido mediante substâncias analgésicas e soporíferas;

E-971 - suicídio e envenenamento autoinflingido por outras substâncias sólidas e líquidas;

E-972 - suicídio e envenenamento autoinflingido pelo gás de uso doméstico;

E-973 - suicídio e envenenamento autoinflingido por outros gases;

E-974 - suicídio e lesão auto-inflingida por enforcamento e estrangulamento;

E-975 - suicídio e lesão auto-inflingida por submersão (afogamento);

E-976 - suicídio e lesão auto-inflingida por armas de fogo e explosivos;

E-977 - suicídio e lesão auto-inflingida por instrumentos cortantes e perfurantes;

E-978 - suicídio e lesão auto-inflingida por precipitação de lugares elevados;

E-979 - suicídio e lesão auto-inflingida por outros processos e processos não especificados.

Nos dados de suicídio do município de São Paulo, relativos ao período de 1959 a 1968, não encontramos - em nenhuma vez - a associação entre essas rúbricas e a de n. ${ }^{\circ}$ E-963 - efeito tardio de ferimento auto-inflingido - Pela razão exposta, serão focalizados somente os óbitos subordinados às rubricas E-970 a E-979.

0 atraso com que os dados oficiais dos óbitos são geralmente divulgados explica a não inclusão dos referentes aos anos de 1969 e seguintes, que ensejariam uma idéia mais próxima do problema do suicídio na área em estudo.

Os dados, tanto de óbitos por suicídio como de população, foram obtidos na Divisão de Estatística Demográfica do De- partamento de Estatística da Secretaria de Economia e Planejamento do Governo do Estado de São Paulo, cujo material foi gentilmente colocado à nossa disposição.

A exemplo do que fizemos em trabalho anterior (RAMOS \& BARBOSA $(1965)^{2}$ ), decidimos incluir em nosso estudo o grupo etário de 0 a 14 anos ao estudarmos o comportamento do suicídio segundo a idade, geralmente posto de lado nos trabalhos que tivemos ocasião de consultar. Por outro lado, já em relação ao grupo de idade ignorada, o pequeno número de óbitos nessa circunstância justificou, durante a análise, o seu abandono.

Deixamos de apresentar o estudo da mortalidade por suicídio segundo a cor pelo fato de que o Departamento de Estatística, tendo em conta as dificuldades existentes na classificação das pessoas por este atributo, tanto em relação aos dados de óbitos como aos de população, já apontadas pelos diversos autores nacionais que se têm ocupado com o assunto, deixou de tabular e apresentar os óbitos por suicídio segundo o atributo em apreço.

A técnica estatística utilizada para analisar o comportamento dos sexos masculino e feminino em relação ao declínio observado na mortalidade por suicídio, durante o período de 1959 a 1968, foi a seguinte: (1) verificação da existência ou não de regressão significante, através do coeficiente $b$, tanto para o sexo masculino como para o feminino, por meio da análise de variância; (2) aplicação de teste entre os dois coeficientes de regressão $b$, pela distribuição " $t$ " de Student. Em ambos os casos, o nível de rejeição foi menor ou igual do que 0,05 .

\section{ANALISE E DISCUSSAO}

Ramos \& Barbosa (1965)2 mostraram que o suicídio no município de São Paulo, durante os 15 anos que vão de 1948 a 1962, no que tange à sua freqüência e à sua tendência temporal, caracterizou-se, 
BARBOSA, V. - Estudo descritivo do suicídio no município de São Paulo (Brasil) - 1959 a 1968. Rev. Saúde públ., S. Paulo, 8: 1-14, 1974.

respectivamente, pelos seguintes aspectos: (1) ocorreram 6.000 óbitos por essa causa de morte; (2) havia duas fases antagônicas nessa curva cronológica: uma, ascendente, de 1948 a 1955; e outra, de 1956 a 1962, decrescente.

A Tabela 1 e a Figura 1, em que apresentamos os coeficientes anuais de mortalidade por suicídio, entre nós, nos 10 anos que medeiam de 1959 a 1968 , revelamnos que esse declínio da mortalidade por essa causa de morte continuou a ser observado. embora com leves oscilaçōes de um ano para outro, durante os seis anos de 1963 a 1968, período este em que ocorreram 2.550 óbitos por suicídios, ou seja. aproximadamente $57 \%$ dos 4.488 óbitos registrados no período de 1959 a 1968. Portanto, os fatores que estavam influenciando o suicídio no sentido da sua diminuição de 1955 a 1962, continuavam presentes, no nosso município. durante os anos de 1963 a 1968.

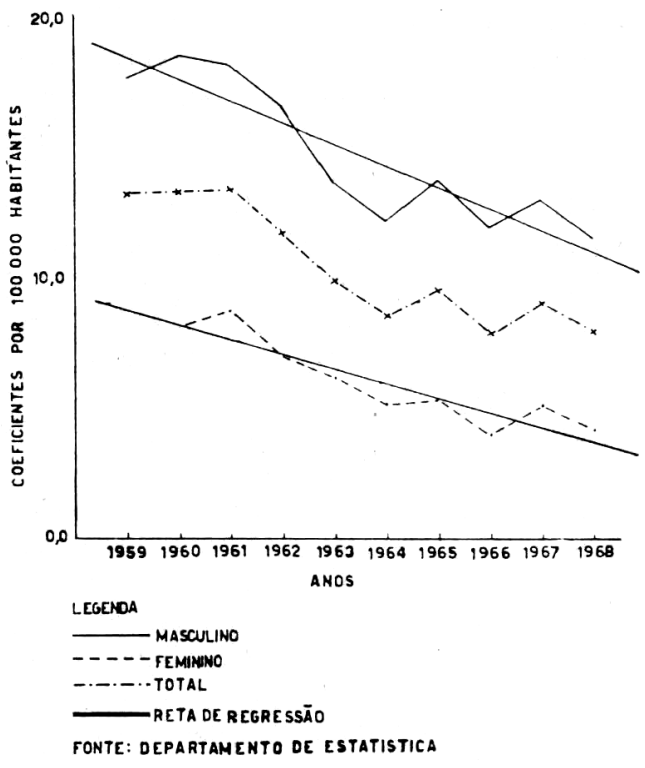

Fig 1 - Mortalidade por suicidio, segundo o sexo, no municipio de São Paulo - 1959 a 1968 icoeficientes médıos por 100.000 habitantes.

TA B E L A 1

Mortalidade por suicídio, segundo o sexo, no municipio de São Paulo, 1959 a 1968 (Coeficientes por 100.000 habitantes)

\begin{tabular}{|c|c|c|c|c|c|c|}
\hline \multirow{2}{*}{ Anos } & \multicolumn{2}{|c|}{ Masculino } & \multicolumn{2}{|c|}{ Feminino } & \multicolumn{2}{|c|}{ Total } \\
\hline & óbitos & Coeficientes & obitos & Coeficientes & obitos & Coeficientes \\
\hline 1959 & 304 & 17,7 & 153 & 8,7 & $45 \pi$ & 13,1 \\
\hline 1960 & 335 & 18,5 & 150 & 8,1 & 485 & 13.2 \\
\hline 1961 & 347 & 18,1 & 170 & 8,7 & 517 & 13,3 \\
\hline 1962 & 334 & 16,6 & 145 & 7,0 & 479 & 11,7 \\
\hline 1963 & 290 & 13,7 & 132 & 6,1 & 422 & 9,8 \\
\hline 1964 & 270 & 12,1 & 116 & 5,1 & 386 & 8,5 \\
\hline 1965 & 324 & 13,8 & 127 & 5,3 & 451 & 9.5 \\
\hline 1966 & 293 & 11,9 & 101 & 4,0 & 394 & 7,9 \\
\hline 1967 & 334 & 13,0 & 134 & 5,1 & 468 & 9,0 \\
\hline 1968 & 314 & 11,5 & 115 & 4,2 & 429 & 7,9 \\
\hline
\end{tabular}

Fonte: Departamento de Estatística da Secretaria de Economia e Planejamento do Estado de São Paulo. 
BARBOSA, V. - Estudo descritivo do suicidio no municipio de São Paulo (Brasil) - 1959 a 1968. Rev. Saúde públ., S. Paulo, 8: 1-14, 1974.

Nessa mesma Tabela e mesma Figura, apresentamos também os coeficientes anuais de mortalidade por suicídio pelos sexos masculino e feminino, relativos ao intervalo de tempo de 1959 a 1968, visando à verificação da influência de cada um dos sexos sobre a curva cronológica descendente do suicídio em nossa comunidade, nesse período, antes referida. Em seguida, aplicamos a técnica estatística descrita no capítulo de material e métodos. Tendo havido significância estatística para o sexo masculino e para o feminino, fizemos o teste entre os dois $b$ pela distribuição " $t$ " de Student; como o resultado se mostrou não significante ao nível crítico considerado, não nos foi possível rejeitar a hipótese de igualdade entre os $b$, fato este indicativo de que os sexos masculino e feminino comportaram-se de modo semelhante quanto à inclinação da curva representativa de suicídio, observada em nosso município no período de 1959 a 1968.

Tendência da mortalidade por suicídio, segundo as causas exógenas

A mortalidade por suicídio, segundo as causas exógenas, no decênio de 1959 a 1968 apresentou alterações relevantes, dignas de serem apontadas, tanto no que concerne à principal dessas causas como no que diz respeito ao escalonamento das mesmas em ordem decrescente de importância, conforme poderemos verificar pelo exame da Tabela 2 e da Figura 2, em que temos os coeficientes médios por suicídio por 100.000 habitantes, segundo as causas exógenas, correspondentes aos períodos de 1959 a 1961 e 1966 a 1968.

A Figura 2 mostra-nos que no primeiro desses triênios a rubrica E-971 (suicídio por outras substâncias sólidas e líquidas) destacou-se francamente entre as causas exógenas de suicídio; além disso, evidencia, também, que à rubrica E-971 seguiram-se, em ordem decrescente de importância, as rubricas E-976 (suicídio por

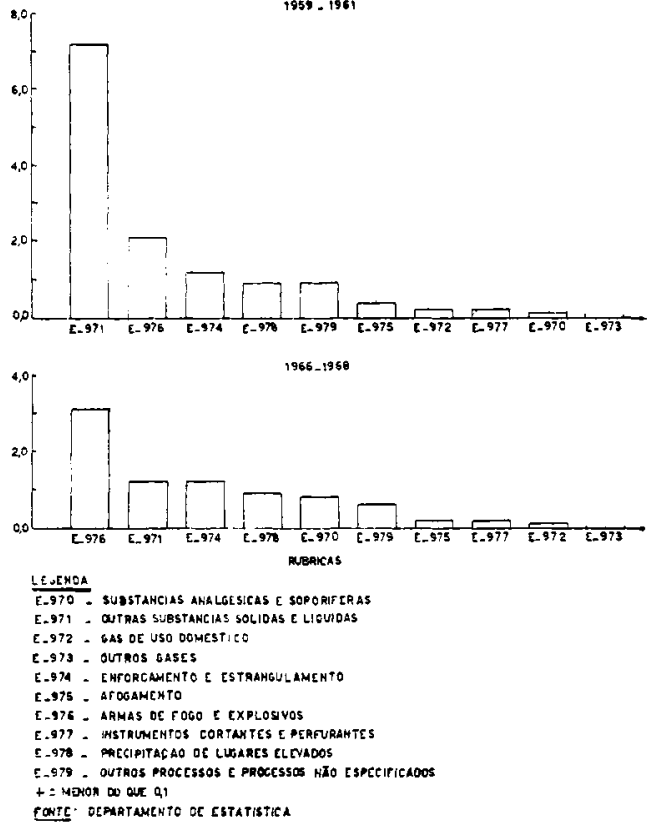

Fig. 2 - Mortalidade por suicídio, segundo as causas exógenas, no município de são Paulo - 1959 a 1961 e 1966 a 1968 (coeficientes médios por 100.000 habitantes).

armas de fogo e explosivos), E-974 (suicídio por enforcamento e estrangulamento), E-978 (suicídio por precipitação de lugares elevados) e E-979 (suicídio por outros processos e processos não especificados). Estas duas últimas em pé de igualdade com coeficientes iguais a 0,9 por 100.000 habitantes. Por fim, revelanos a pequena importância assumida pelas demais rubricas como causas exógenas de suicídio no município de São Paulo, nesse período.

Era tão flagrante o destaque assumido pela rubrica E-971 sobre as quatro outras rubricas, que se thes seguiram em ordem decrescente de importância, e sobre as nove restantes rubricas, que, se partirmos dos dados da Tabela 2 poderemos verificar que o coeficiente de mortalidade da E-971 $(7,2)$ era maior do que o total obtido pela soma dos coeficientes 
BARBOSA, V. - Estudo descritivo do suicidio no municipio de São Paulo (Brasil) - 1959 a 1968. Rev. Saude públ., S. Paulo, 8: 1-14, 1974.

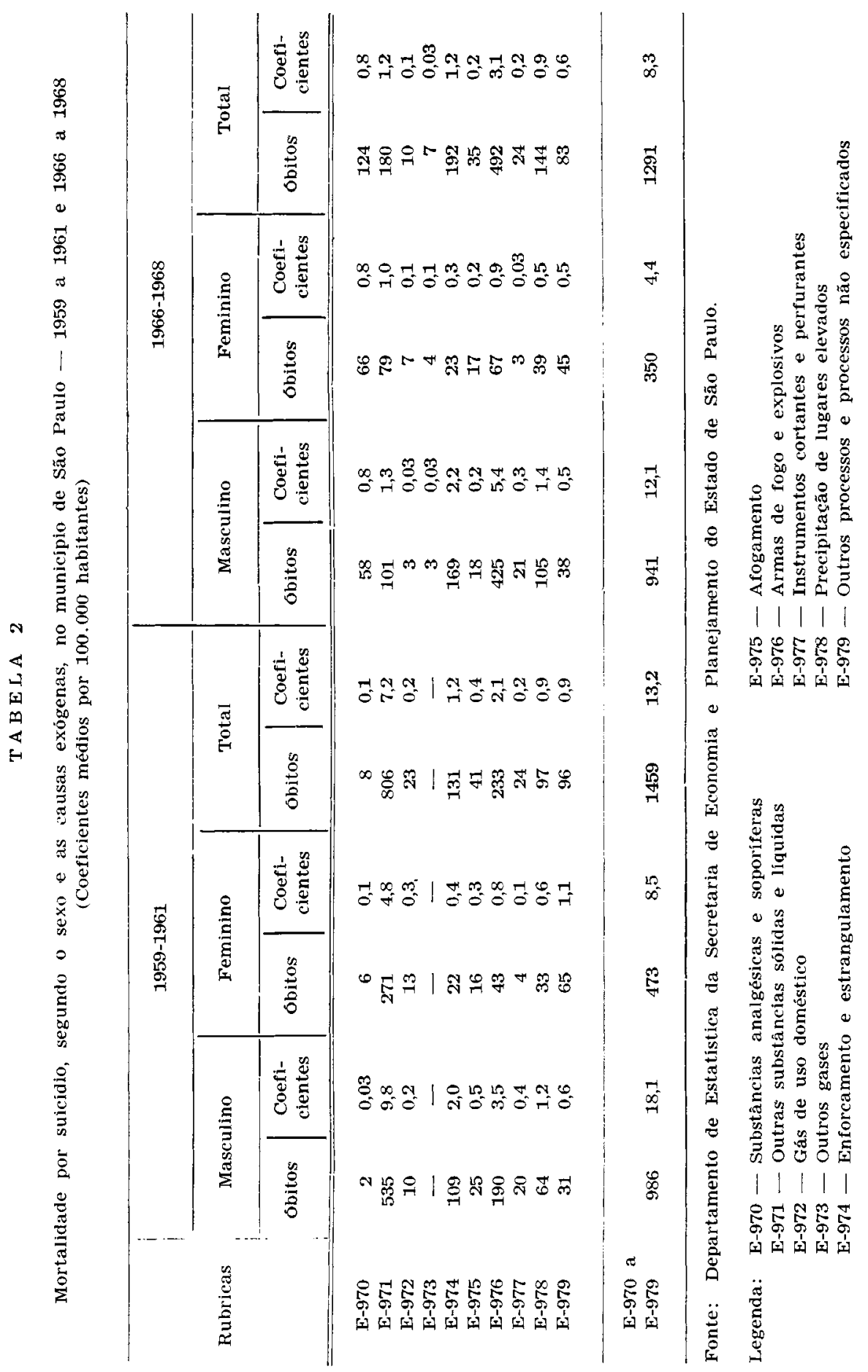


BARBOSA, V. - Estudo descritivo do suicidio no municipio de Săo Paulo (Brasil) - 1959 a 1968. Rev. Saúide públ., S. Paulo, 8: 1-14, 1974.

daquelas quatro rubricas $(5,1)$ e do que a total derivado da soma dos coeficientes das nove citadas rubricas $(6,0)$ nas proporçôes, respectivamente, de $1,4: 1$ e 1,2:1. Era de se notar também que em relação à própria rubrica E-976, que se seguira imediatamente à E-971 em ordem de importância, o coeficiente de mortalidade desta última mostrara-se substancialmente maior, na proporção de $3,4: 1 \quad(7,2: 2,1$ por 100.000 habitantes).

Já em relação ao período de 1966 a 1968, a mesma Figura mostra que o comportamento das causas exógenas do suicídio no município de São Paulo, quando comparado ao observado nos anos de 1959 a 1961, apresentou duas diferenças dignas de serem mencionadas: (a) a rubrica $E$ 971 que, no período de 1959 a 1961, destacara-se nitidamente das demais, foi, durante os anos de 1966 a 1968, claramente suplantada pela E-976, colocando-se, portanto, esta última em primeiro lugar como causa exógena de suicídio, ficando a E-971 colocada logo em seguida; (b) a rubrica E-970 (suicídio por substâncias analgésicas e soporíferas) que de 1959 a 1961 se mostrara absolutamente desprovida de importância como causa exógena de suicídio, eis que, então, se encontrava colocada em nono lugar, adquiriu certa importância como causa exógena de suicídio no período de 1966 a 1968, quando se colocou na quinta posição e, portanto, entre as cinco causas exógenas principais de suicídio nesse período, tendo deslocado a E-979 para o posto seguinte.

Com efeito, o exame da Tabela 2 permite-nos verificar, neste último período, que o coeficiente de mortalidade por suicídio devido à rubrica E-976 (3,1) foi maior do que o da rubrica E-971 $(1,2)$, guardando entre eles uma relação de 2,6:1. Isto deveu-se ao fato de que, enquanto que o coeficiente devido à rubrica E-971 que, de 1959 à 1961, era igual a 7,2, passou, no triênio de 1966 a 1968, a ter - valor de 1,2, tendo, portanto, sofrido uma redução de seis vezes, o coeficiente da E-976, por sua vez, igual a 2,1 no período de 1959 a 1961, elevou-se para 3,1 no triênio de 1966 a 1968, tendo, pois, sofrido uma elevação da ordem de 1,5 vezes. Essa mesma Tabela mostra-nos, por outro lado, que o coeficiente da rubrica E-970, de 0,1 em 1959 a 1961, passou para 0,8 em 1966 a 1968, aumentando oito vezes; enquanto isso, o coeficiente da rubrica E-979, em 1959 a 1961 igual a 0,9, reduziu-se, em 1966 a 1968, para 0,6.

\section{Tendência da mortalidade por suicidio segundo o sexo e as cinco causas exógenas principais}

No município de São Paulo, durante o triênio de 1959 a 1961 e o período de 1966 a 1968, a mortalidade por suicídio, por todas as causas e segundo o sexo, apresentou, respectivamente, as relações de 2,1:1 e 2,8:1, conforme podemos verificar pelo exame da Tabela 2 , na qual temos, para o primeiro desses períodos, um coeficiente de 18,1 para o sexo masculino e de 8,5 para o feminino, enquanto que, no triênio de 1966 a 1968, os coeficientes correspondentes aos sexos, na ordem antes apontada, são iguais a 12,1 e 4,4 por 100.000 habitantes. Isto, sem dúvida, está a evidenciar uma tendência no sentido de uma predominância do suicidio, cada vez maior no sexo masculino em relação ao feminino, à medida que nos aproximamos da época atual.

No que tange à individualização da principal das causas exógenas de suicídio e do escalonamento das cinco principais delas, em ordem decrescente de valor, segundo um e outro sexo, em cada um dos períodos antes citados, o estudo da Tabela 2 e da Figura 3 traz à tona consideraçōes de interesse epidemiológico que passaremos a expor em seguimento.

No triênio de 1959 a 1961, a apreciação da Figura 3 permite-nus verificar que se sobressaiu, tanto entre os homens como entre as mulheres, a rubrica E-971 
BARBOSA, V. - Estudo descritivo do suicidio no municipio de São Paulo (Brasil) - 1959 a 1968. Rev. Saúde públ., S. Paulo, 8: 1-14, 1974.

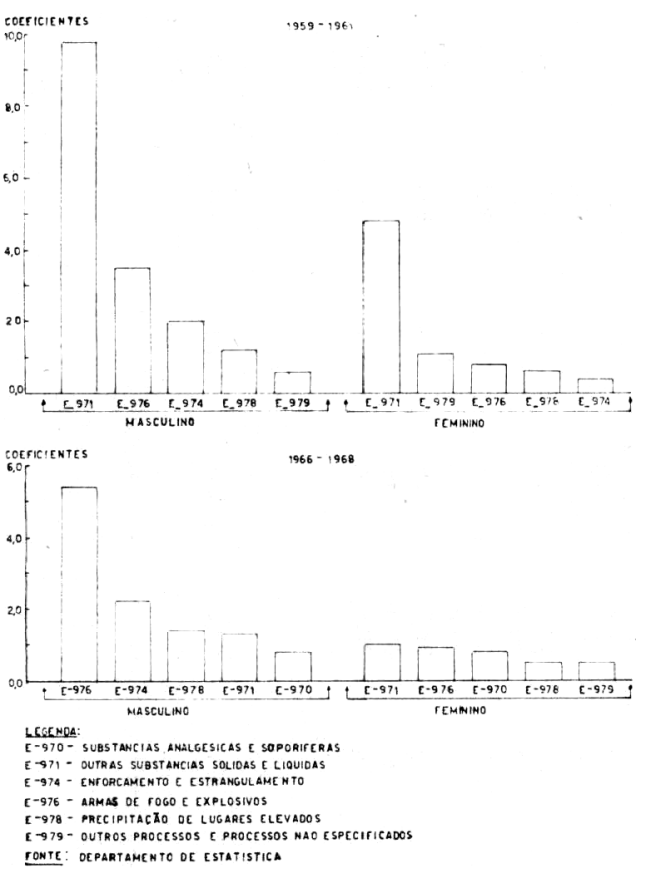

Fig. 3 - Mortalidade por suicidio, segundo o sexo e as cinco causas exógenas principais, no municipio de São Paulo - 1959 a 1961 e 1966 a 1968 (coeficientes médios por 100.000 habitantes).

como causa exógena de suicídio, ao se colocar, num e noutro caso, em primeiro lugar dentre as cinco causas exógenas principais de suicídio em nosso município. No sexo masculino, o seu coeficiente médio de mortalidade por 100.000 habitantes $(9,8)$ foi 2,8 vezes maior do que o da rubrica E-976 (3,5), que se lhe seguiu em ordem de importância, e 1,3 maior do que o coeficiente obtido pela soma dos das quatro rubricas seguintes - E-976, E-974, E-978 e E-979 - igual a 7,3 (Tabela 2). No sexo feminino, por sua vez, o coeficiente médio de mortalidade da rubrica E-971 (4,8) foi maior 4,4 e 1,7 vezes, respectivamente, do que o da rubrica colocada em segundo lugar (E-979, igual a 1,1 ) e o obtido pela soma das quatro rubricas que se lhes segui:am em ordem de importância - E-979, E-976, E-978 e E-974, igual a 2,9 (Tabela 2).

Já no período de 1966 a 1968, a Figura 3 mostra-nos interessantes alterações, num e noutro sexo, quer no que diz respeito à natureza da causa exógena principal de suicídio, quer no que concerne ao escalonamento - em ordem decrescente de valor - das cinco causas exógenas principais de suicídio em nossa comunidade.

No sexo masculino ocorreu o seguinte: (a) a principal causa exógena foi a $\mathrm{E}$ 976 e não a E-971, como ocorrera no período de 1959 a 1961; (b) além disso, a E-971 perdeu muito de sua importância anterior, quando comparada com as demais causas exógenas de suicídio, tanto que se viu deslocada para o quarto lugar, tendo sido suplantada, inclusive, pelas rubricas E-974 e E-978, sobrepujando apenas, por sua vez, a E-970 que, colocandose na quinta posição, pois seu coeficiente - menor do que 0,1 em 1959 a 1961 passou para 0,8 em 1966 a 1968, deslocou a E-979 de dentre as cinco causas exógenas principais de suicídio. Nessas condições, o escalonamento dessas cinco causas exógenas principais - diferente do observado no período de 1959 a 1961 foi o seguinte: E-976, E-974, E-978, E971 e E-970.

A impressão quantitativa do que acabamos de descrever, que reforça o seu significado e importância epidemiológica, temo-la na Tabela 2. Com efeito, partindo-se dos coeficientes de mortalidade médios, para o período em causa, de cada uma dessas cinco causas exógenas, podemos evidenciar que o coeficiente da E$976(5,4)$ mostrou-se maior do que os correspondentes a cada uma das demais causas exógenas, na ordem antes citada, respectivamente nas proporções de 2,5:1, $3,9: 1,4,2: 1$ e $6,8: 1$, eis que esses coeficientes apresentaram valores iguais a 2,2 , $1,4,1,3$ e 0,8 . 
BARbosA, V. - Estudo descritivo do suicídio no municipio de Săo Paulo (Brasil) - 1959 a 1968. Rev. Saúde públ., S. Paulo, 8: 1-14, 1974.

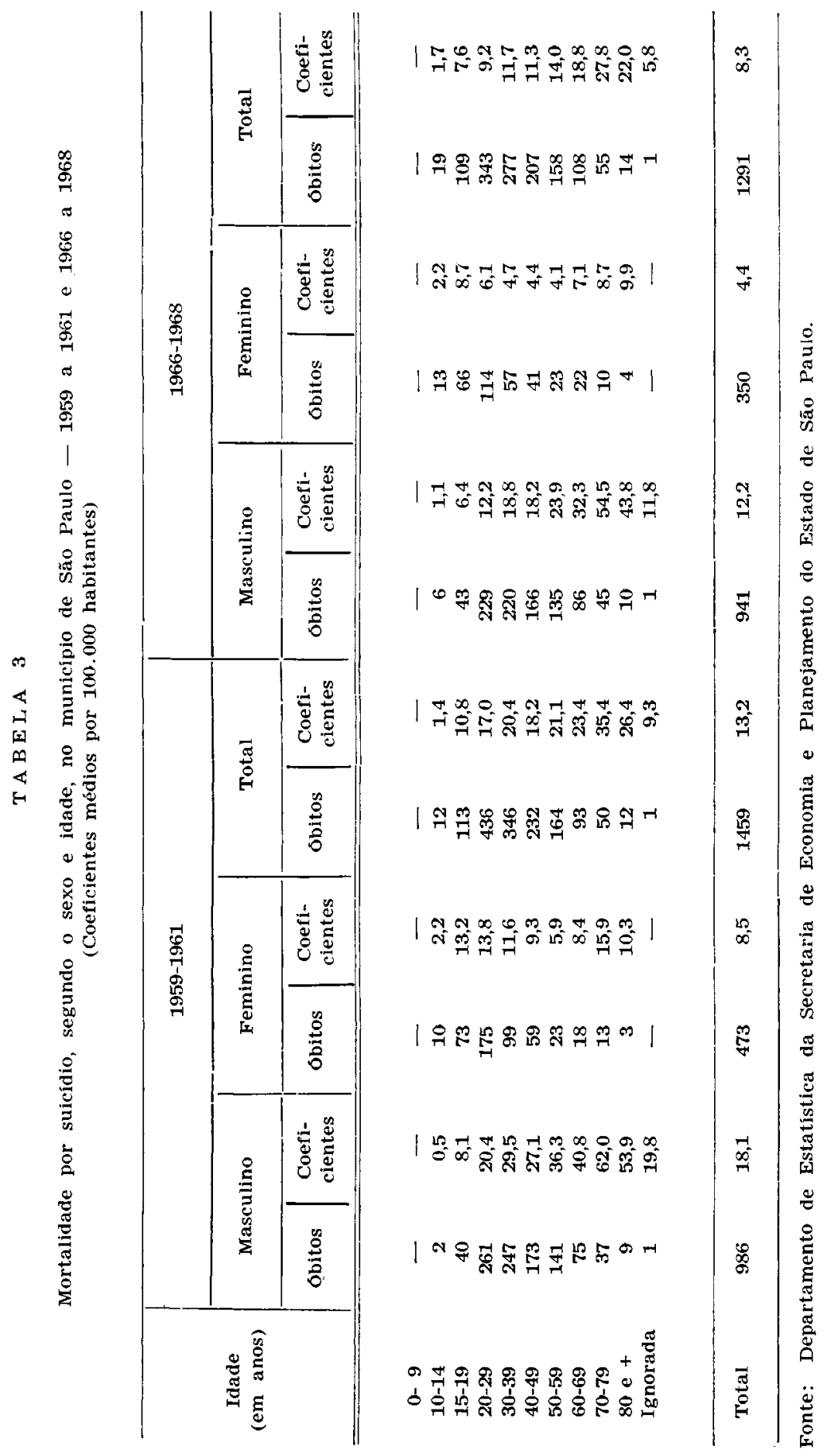


BARBOSA, V. - Estudo descritivo do suicidio no municipio de São Paulo (Brasil) - 1959 a 1968. Rev. Saúde públ., S. Paulo, 8: 1-14, 1974.

No sexo feminino, por outro lado, a mesma Figura 3 revela-nos que: (a) no período de 1966 a 1968 a rubrica E-971 continuou, a exemplo do que já fizera nos anos de 1959 a .1961 , em primeiro lugar, se bem que, agora, quase que em igualdade de condiçôes com a rubrica E976 que se colocou na segunda posição; (b) o escalonamento das cinco causas exógenas principais de suicídio no período de 1966 a 1968, que mostrou certas diferenças com o observado no triênio de 1959 a 1961, foi o seguinte: E-971, E976, E-970, E-978 e E-979.

A apreciação quantitativa desses fatos pode ser feita pelo exame da Tabela 2 . A acentuada diminuição da importância relativa da rubrica E-971 deveu-se ao fato de que o seu coeficiente médio de mortalidade, igual a 4,8 no período de 1959 a 1961, reduziu-se, no triênio de 1966 a 1968, para 1,0, enquanto que o da E-976 mostrou-se, num e noutro desses intervalos de tempo citados, respectivamente iguais a 0,8 e 0,9 por 100.000 habitantes, tendo se mantido, portanto, quando comparado nesses periodos, praticamente constante. As diferenças observadas no escalonamento das cinco causas exógenas principais de suicídio, antes referidas, foram devidas aos seguintes fatos: (a) a rubrica E-970 que no período de 1959 a 1961 não se encontrava entre as cinco primeiras causas exógenas, adquiriu, no triênio de 1966 a 1968 , certa importância ao se colocar na terceira posição, em razão de ter o seu coeficiente de mortalidade se elevado de 8 vezes, passando de 0,1 (em 1959 a 1961) para 0,8 (em 1966 a 1968); (b) a rubrica E-974, quinta colocada no período de 1959 a 1961, deixou, no triênio de 1966 a 1968, de se situar entre as cinco causas exógenas principais de suicídio, tendo o seu coeficiente de mortalidade sofrido leve redução no seu valor neste último período de tempo $(0,3)$ quando comparado com o correspondente de 1959 a $1961(0,4)$.
Em vista do que foi exposto, somos levados a crer que: (a) a inversão observada entre as rubricas E-971 e E-976, quanto a sua ordem de importância como causa exógena de suicídio entre os nossos munícipes, nos períodos de tempo de 1959 a 1961 e 1966 a 1968, conforme vimos no item "Tendência da mortalidade por suicídio segundo as causas exógenas", deveu-se, quase que exclusivamente, à mudança de comportamento do sexo masculino na escolha da maneira de se suicidar; (b) quanto à importância adquirida pela rubrica E-970 como causa exógena de suicídio no período de 1966 a 1968 , em contraste com a sua inexpressividade, como tal, nos anos de 1959 a 1961, tanto o sexo masculino como o feminino influiram, nesse sentido, praticamente em igualdade de condições.

Tendência da mortalidade por suicídio, segundo idade e sexo

Os óbitos por suicídio no município de São Paulo, segundo a idade, os sexos masculino e feminino e em ambos os sexos, durante os triênios de 1959 a 1961 e 1966 a 1968, são apresentados, em termos de coeficientes médios por 100.000 habitantes na Tabela 3 e na Figura 4.

A Figura 4 mostra-nos que no período de 1959 a 1961 as curvas de evolução do suicídio do sexo masculino e de ambos os sexos são praticamente as mesmas. Com efeito, uma e outra revelam uma tendência nitidamente ascendente com o aumento das idades até o grupo etário de 30 a 39 anos, quando sofrem certa redução de valor no grupo etário de 40 a 49 anos para, em seguida, retomarem o seu aspecto francamente ascendente até 70 a 79 anos, onde atingem o seu máximo valor, para, depois, diminuirem de intensidade no grupo etário de 80 e mais anos. Em resumo, os grupos etários mais atingidos foram os mais velhos, na seguinte ordem: 70 a 79 anos, 80 e mais, 60 a 69 anos e 50 a 59 anos, cabendo aos mesmos atingidos - em escalonamento 
BARbosa, V. - Estudo descritivo do suicidio no municiplo de são Paulo (Brasil) - 1959 a 1968. Rev. Saúde públ., S. Paulo, 8: 1-14, 1974.
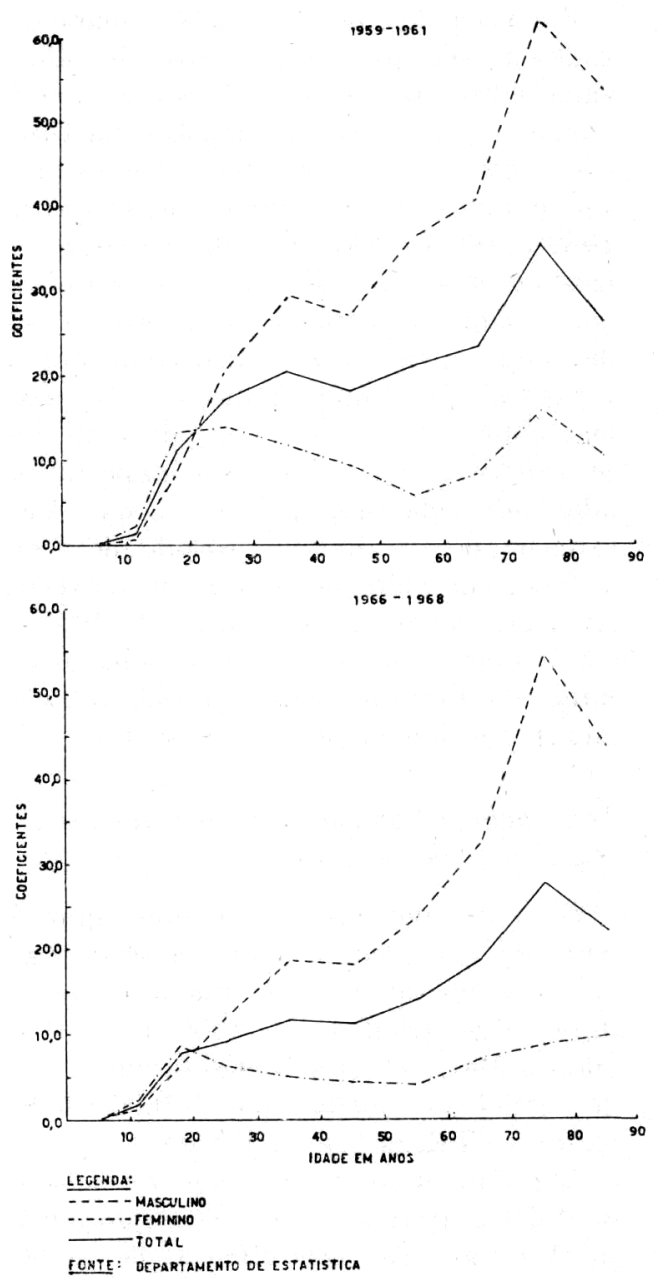

Fig. 4 - Mortalldade por suicidio, segundo o sexo e idade, no municipio de são Paulo 1959 a 1961 e 1966 a 1968 (coeficientes médios por 100.000 habitantes).

crescente e com exceção dos de 0 a 9 e 10 a 14 anos que, como vimos em trabalho anterior ${ }^{2}$, carecem, respectivamente, de nula ou mínima importância os grupos etários de 15 a 19 e 20 a 29 anos.

Essa mesma Figura permite-nos verificar que no período de 1966 a 1968 , no sexo masculino e em ambos os sexos, a distribuição da mortalidade por suicídio pelos grupos etários, em nosso município, manteve-se inalterável, fato este indicativo de que o suicídio, entre nós, comportou-se de modo idêntico, num e noutro dos períodos considerados, em relação às. variáveis antes mencionadas.

No sexo feminino, a apreciação da Figura 4 evidencia uma curva etária do suicídio, relativa aos anos de 1959 a 1961, que apresenta aspecto evolutivo diferente do observado para o sexo masculino, nesse mesmo período. Realmente, essa curva apresenta os seguintes característicos: (a) ascendente até 0 grupo etário de 20 a 29 anos, em seguida torna-se descendente até as idades de 50 a 59 anos para, depois, subir, novamente, até o grupo etário de 70 a 79 anos e, finalmente, cair nas idades de 80 e mais anos; (b) os grupos etários que apresentaram os maiores coeficientes médios de mortalidade por suicídio foram os de 70 a 79,20 a 29 e 15 a 19 anos, ao passo que os de menores coeficientes foram os de 50 a 59 , 60 a 69 e 40 a 49 anos. Nota-se, pois, nesse sexo e nesse período, ao contrário do ocorrido com o sexo masculino na mesma época, uma certa tendência das mulheres em se suicidarem nas idades mais jovens, sobretudo de 15 a 29 anos.

Nesse mesmo sexo, podemos ver ainda pelo exame da Figura 4 que no período de 1966 a 1968, mais recente, a curva etária do suicídio segue, em linhas gerais, o padrão verificado nos anos de 1959 a 1961, com a diferença de que os grupos etários com os maiores coeficientes médios de mortalidade por suicidio foram os de 80 e mais, 15 a 19 e 70 a 79 anos (estes dois últimos com o mesmo coeficiente), cabendo os menores coeficientes às idades de 50 a 59,40 a 49 e 30 a 39 anos. Portanto, neste último período de tempo - 1966 a 1968 - percebe-se um certo deslocamento do suicídio, entre as mulheres, para os grupos etários mais velhos, mas mantem-se, ainda, o grupo etário de 15 a 19 anos em posição de re- 
BARBOSA, V. - Estudo descritivo do suicídio no município de São Paulo (Brasil) — 1959 a 1968. Rev. Saúde pübl., S. Paulo, 8:1-14, 1974.

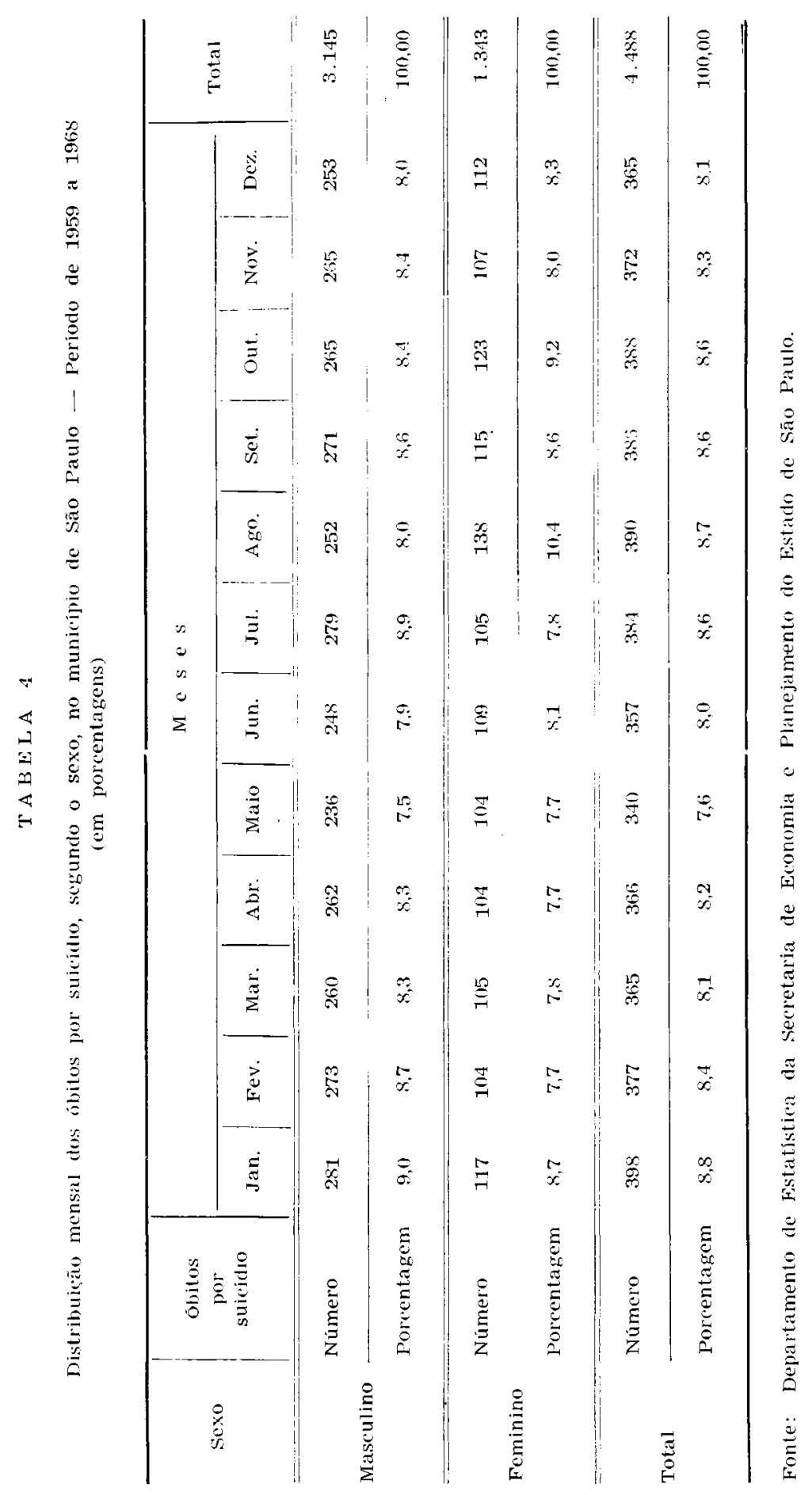


Barbosa, V. - Estudo descritivo do suicídio no municipio de São Paulo (Brasil) - 1959 a 1968. Rev. Saúde públ., S. Paulo, 8: 1-14, 1974.

levo no que diz respeito ao suicídio entre as mulheres, em nosso município, nos anos mais recentes.

\section{Distribuição mensal dos óbitos por suicidio, segundo o sexo}

O total de óbitos por suicídio, segundo os sexos masculino, feminino e em ambos os sexos, ocorridos nos 10 anos de 1959 a 1968 no município de São Paulo, são apresentados na Tabela 4 e na Figura 5.

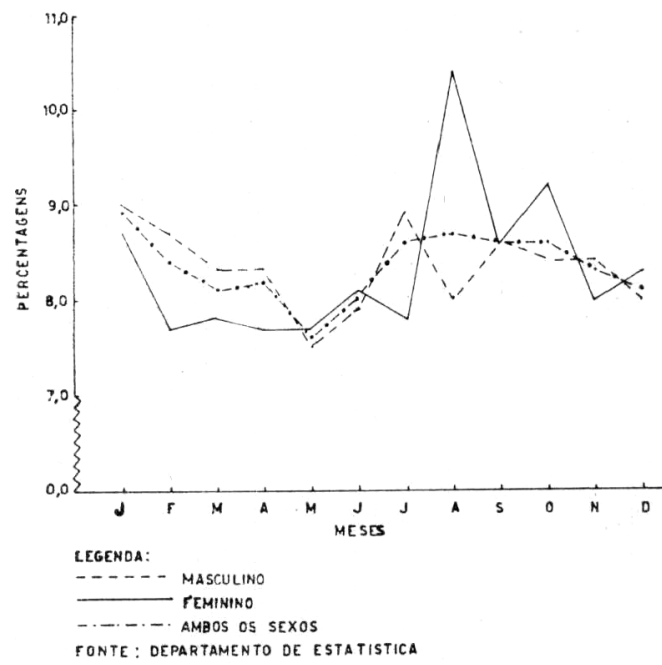

Fig. 5 - Distribuicãa mensal dos b́bitos por sulcídio, segundo o sexo, no municiplo de São Paulo - periodo de 1959 a 1968 (em porcentagens).

Pela sua análise, podemos observar que no sexo masculino e em ambos os sexos não há uma distribuição mensal peculiar dos seus óbitos, visto que eles se distribuem quase que homogeneamente por todos os meses. Já no que tange ao sexo feminino, notamos claramente uma distribuição mensal dos óbitos caracterizada por um pico - bastante acentuado no mês de agosto, cujo valor é igual a $10,4 \%$, seguido, em ordem de magnitude decrescente, pelas percentagens dos meses de outubro $(9,2)$, janeiro $(8,7)$ e setem- bro $(8,6)$; os demais meses apresentam percentagens menores do que as citadas, que variam desde 7,7 para os meses de fevereiro, abril e maio, os meses de menor incidência, até 8,3 para o mês de dezembro.

\section{CON CIUSOES}

1. A curva cronológica do suicídio no município de São Paulo, descendente durante o período de 1955 a 1962 , continuou, durante os anos de 1963 a 1968, a diminuir de intensidade.

2. Essa inclinação descendente da curva temporal do suicídio, observada durante os 10 anos de 1959 a 1968 , foi semelhantemente influenciada pelos sexos masculino e feminino.

3. Durante o decênio de 1959 a 1968 ocorreram alterações no comportamento das causas exógenas do suicídio em nosso município, dignas da nossa atenção: (a) no triênio de 1966 a 1968 a rubrica $1-976$ colocouse em primeiro lugar, suplantando claramente a E-971, situada logo a seguir, invertendo-se assim, dessa maneira, as posições ocupadas por essas rubricas durante os anos de 1959 e 1961 quando, em contraste, a E-971 se colocara em primeiro lugar, sobrepujando nitidamente a E976; (b) a rubrica E-970 que de 1959 a 1961 se mostrara absolutamente desprovida de importância como causa exógena de suicídio, adquiriu, no período de 1966 a 1968, certa importância, como tal, ao se colocar entre as cinco causas exógenas principais de suicídio nesse periodo.

4. A medida que nos aproximamos da época atual, evidencia-se uma tendência no sentido de uma predominância do suicídio, cada vez maior no sexo masculino em relação ao feminino, eis que as relações entre os coeficientes de mortalidade por suicídio nesses 
BARBOSA, V. - Estudo descritivo do suicidio no municipio de São Paulo (Brasil) - 1959 a 1968. Rev. Saúde públ., S. Paulo, 8: 1-14, 1974.

dois sexos, na ordem apontada, nos períodos de 1959 a 1961 e 1966 a 1968 , foram respectivamente, iguais a 2,1:1 e 2,8:1, a favor do sexo masculino.

5. A inversão observada entre as rubricas E-971 e E-976, quanto a sua ordem de importância como causa exógena de suicídio, nos períodos de 1959 a 1961 e 1966 a 1968 , deveuse, quase que exclusivamente, à mudança de comportamento do sexo masculino na escolha de maneira de se suicidar.

6. No que tange à importância adquirida pela rubrica E-970 como causa exógena de suicídio no período de 1966 a 1968, em contraste com a sua inexpressividade, como tal, nos anos de 1959 a 1961, tanto o sexo masculino como o feminino influiram, nesse sentido, praticamente em igualdade de condições.

7. No sexo masculino e em ambos os sexos, tanto no período de 1959 a 1961 como no de 1966 a 1968, a distribuição do suicídio pelas idades manteve-se praticamente inalterável, caracterizando-se pelos seguintes fatos: (a) os grupos etários mais atingidos foram os mais velhos, de 50 anos em diante; (b) os grupos etários menos atingidos foram os mais jovens, de 15 a 29 anos.

8. No sexo feminino, a distribuição etária do suicídio foi diferente da observada para o sexo masculino e apresentou, além disso, características diferentes nos períodos de 1959 a 1961 e 1966 a 1968; assim é que podemos perceber que no primeiro desses períodos há, apesar do grupo etário de 70 a 79 anos ser bastante atingido, uma certa tendência das mulheres em se suicidarem nas idades mais jovens, sobretudo de 15 a

19 e 20 a 29 anos, enquanto que, no segundo período, há um certo deslocamento do suicídio, entre as mulheres, para os grupos etários mais velhos, de 70 a 79 e de 80 e mais anos, mas o grupo etário de 15 a 19 anos ainda se mantém em posição de destaque.

9. No que tange à distribuição estacional do suicídio, segundo os sexos masculino, feminino e em ambos os sexos, no decênio de 1959 a 1968, - único fato que merece destaque é a presença de um pico - bastante acentuado - no mês de agosto no sexo feminino.

RSPU-B/198

BARBOSA, V. - [A descriptive study of suicide in the county of S. Paulo (Brazil) from 1959 to 1968.] Rev. Saúde públ., S. Paulo, 8: 1-14, 1974.

SUMMARY: Based in the official data it was made an epidemiological retrospective descritive study about the mortality caused by suicide in the county of S. Paulo, Brazil. This study also includes the trends of some epidemiological characters for this couse of death, from 1959 to 1968, which are: exogenous causes, chronologic distribution, monthly distribution and distribution in sex and age.

UNITERMS: Suicide*; Mortality*; Epidemiology*. 
BARBosA, V. - Estudo descritivo do suicídio no município de São Paulo (Brasil) - 1959 a 1968. Rev. Saúde públ., S. Paulo, 8: 1-14, 1974.

\section{REFERENCIAS BIBLIOGRÁFICAS}

1. MANUAL de classificacão estatística internacional de doenças, lesões e causas de morte: 7.a revisão de 1955. Washington, D.C., Organização Panamericana da Saúde, 1964. 2 v.

2. RAMIOS, R. \& BARBOSA, V. - Estudos sobre a mortalidade por suicídio. I.
Discussão sobre seu valor como indicador do nível de saúde mental. II. A mortalidade por suicídio no município de São Paulo. Arq. Fac. Hig. S. Paulo, 19: 33-66, 1965.

Recebido para publicacão em 30-10-19ra Aprovado para publicaça em 21-1-197' 